\title{
Construction of an inexpensive sun photometer to measure aerosol optical depth and comparisons between the measured data and satellite observations
}

\author{
Pallab Kumar Mondol, Md Mainul Islam Mamun*, Md Monirul Islam \\ Department of Applied Physics and Electronic Engineering, University of Rajshahi, Rajshahi-6205, Bangladesh \\ Email address: \\ pallabapee_ru@yahoo.com (P. K. Mondol), mainul_apee@yahoo.com (M. M. I. Mamun), rajib_apee@yahoo.com (M. M. Islam)
}

\section{To cite this article:}

Pallab Kumar Mondol, Md Mainul Islam Mamun, Md Monirul Islam. Construction of an Inexpensive Sun Photometer to Measure Aerosol Optical Depth and Comparisons between the Measured Data and Satellite Observations. American Journal of Remote Sensing. Vol. 2, No. 5, 2014, pp. 37-43. doi: 10.11648/j.ajrs.20140205.11

\begin{abstract}
At present the absorption and scattering of solar radiation by aerosols have been recognized as important parameters for climate change. A way of probing the atmosphere from the ground is to measure the effects of the atmosphere on sunlight transmitted to Earth's surface. This indirect technique provides information about the entire atmosphere above the observer. This paper describes a new kind of inexpensive two channels LED sun photometer for monitoring aerosols that provide long-term stability. In this study, we have constructed a handheld sun photometer and used it to measure and monitor the aerosol optical depth (AOD) and compared the measured values with the satellite data. The ground based measurements of $\mathrm{AOD}$ at $550 \mathrm{~nm}$ from a handheld sun photometer is compared with the Terra and Aqua MODerate Resolution Imaging Spectroradiometers (MODIS) AOD retrievals over the region of Rajshahi division, Bangladesh for the 15 days duration of June 2012. The results indicate that the constructed handheld sun photometer measurements have good correlations with Terra and Aqua MODIS retrievals with correlation coefficients $r=0.88$ for Terra and $r=0.55$ for Aqua whereas correlation coefficients between Terra and Aqua is 0.65 . AOD at $625 \mathrm{~nm}$ is also documented to find out the relation of AOD at different wavelengths.
\end{abstract}

Keywords: Aerosol, Aerosol Optical Depth, Constructed Inexpensive Sun Photometer, Terra and Aqua MODIS

\section{Introduction}

The transparency of the atmosphere plays a vital role in modulating climate. Atmospheric gases and their cargo of tiny suspended particles known as aerosols reduce the transmission of a direct beam of sunlight through the atmosphere [5]. This reduction is known as extinction, and its magnitude is commonly expressed in terms of optical depth or thickness known as Aerosol Optical Depth (AOD), a dimensionless figure of merit [5]. Aerosols influence the radiation balance through two key processes: directly and indirectly [14]. The first mechanism by which aerosols influence our climate system is by reflecting and absorbing solar radiation and infrared thermal radiation from the Earth's surface [7]. Some aerosol like black carbon absorbs radiation at long wavelength thus warming the Earth's climate system. Other species like desert dust effectively scatter solar radiation which is responsible for cooling the Earth's climate system. The second mechanism is by using as condensation nuclei for water vapor, thereby enhancing the process of cloud forming, resulting in more clouds which consist of more cloud droplets of smaller in size. This increases both the reflectivity and lifetime of clouds [7].

The maximum distance that an object is visible is determined by the scattering and extinction of light by gas molecules and particles [1]. The particles are more important in determining visibility. Near centers of human activities, the quantity of suspended particles drastically increases and thus visibility decreases. The Moderate Resolution Imaging Spectroradiometer (MODIS) onboard the National Aeronautics and Space Administration's (NASA) Terra and Aqua satellites have been monitoring daily aerosol optical thickness worldwide [1]. For proper observation of AOD of a particular area AERONET (Aerosol Robotic NETwork - a network of ground-based sun photometers) is used for field based measurement [3]. But there was no station of AERONET in Bangladesh for observing AOD during the study period. In this paper, we present the results of aerosol optical depth measurements taken by MODIS instrument of 
Terra and Aqua satellites. Visibility measurements have been taken from handheld sun photometer observations in Rajshahi division for 15 days duration of June 2012. This is the first time that such data are reported for Rajshahi.

Instruments that measure the intensity in a direct beam of sunlight can measure the optical depth caused by atmospheric gases and aerosols [2]. This handheld sun photometer is based on a non-standard design that uses lightemitting diodes (LEDs) as spectrally selective light sensors, rather than traditional photodiodes and interference filters. The sun photometer has two channels with, respectively at $550 \mathrm{~nm}$ (green channel) and 625nm (red channel). We know higher concentration of aerosol causes lower transmission of solar radiation. The values of AOD in our selected area were very high during measurement which is compared with the satellite based measurement.

\section{Experimental Setup}

\subsection{Study Area}

Bangladesh extends from $20^{\circ} 34^{\prime} \mathrm{N}$ to $26^{\circ} 38^{\prime} \mathrm{N}$ latitude and from $88^{\circ} 01^{\prime} \mathrm{E}$ to $92^{\circ} 41^{\prime} \mathrm{E}$ longitude. The study area used in this investigation is the greater Rajshahi division which extends from $23.403002103211^{\circ}$ to $25.074000120351^{\circ} \mathrm{N}$ latitude and $87.835002132142^{\circ}$ to $89.453001211351^{\circ} \mathrm{E}$ longitude as shown in Fig.1 where inner rectangle of the figure denotes the experimental region.

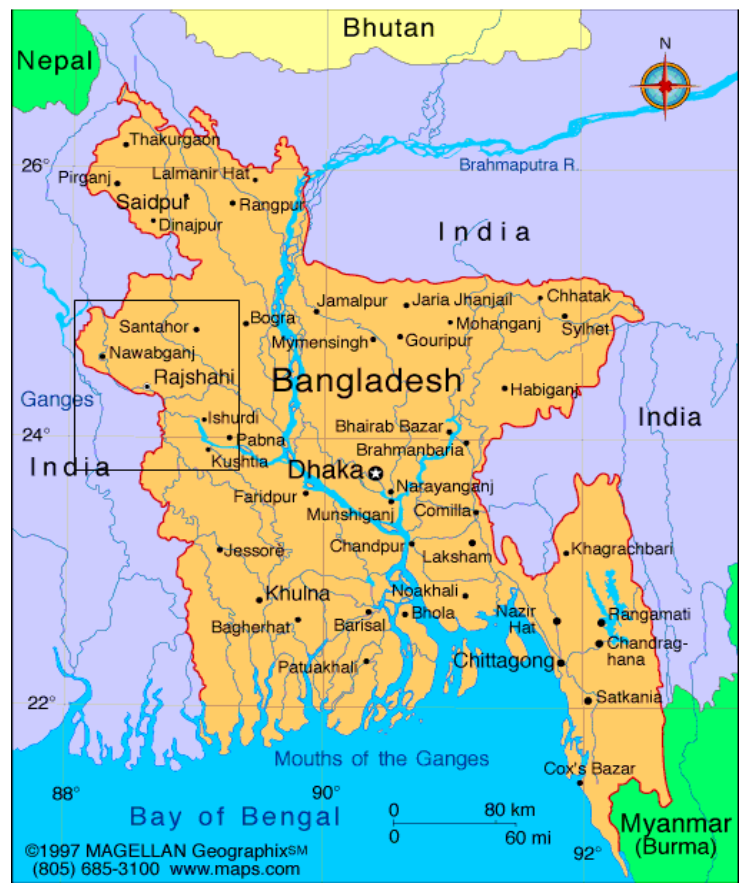

Fig 1. Geographical location of study area as well as Bangladesh.

As average rainfall in Rajshahi division is lower than the other parts of Bangladesh so the natural temperature remains very high especially from April to October for this region. In the present work obtained data from constructed handheld sun photometer have been compared with data retrieved from
Terra and Aqua MODIS satellites. As the area of Bangladesh as well as our selected area is very small from the view of satellite measurement sometimes it was complex to retrieve AOD values during the experiment.

\subsection{Constructed Two Channels Handheld Sun Photometer}

The handheld sun photometer measures attenuation of the direct sunlight as it passes through the atmosphere [1]. The light intensity measured by the sun photometer is not influenced by the atmospheric scattering because of small aperture of the instrument [1]. Light emitting diodes are good detectors of light of specific colors. Generally, the wavelength of light detected by an LED is shorter than the wavelength of light emitted by the same LED. To construct the sun photometer LED detector is used instead of solar cell or photo diode because LED detector has spectral sensitivity and stability of its response [7]. For this it can response in particular wavelength. The spectral band pass of LEDs suitable for sun photometers ranges from about $16 \mathrm{~nm}$ to $100 \mathrm{~nm}$. While this exceeds the $10 \mathrm{~nm}$ band pass of interference filters most commonly used in sun photometers, preliminary comparisons of an LED and filter instrument gave similar results [5]. The sun photometer has been originally developed has two channels in the visible part of the spectrum i.e. $550 \mathrm{~nm}$ (green channel) and $625 \mathrm{~nm}$ (red channel).

In operation, light from the sun causes the LED detector to generate a tiny electrical current which goes to the operational amplifier that transforms to a voltage and boosted by the amount of the feedback resistance. The amplifier boosts the signal from the LED by a factor of the value of feedback resistor as shown in Fig.2. A 9 volt battery is present to supply power to the LEDs. The voltage from the amplifier is measured with a digital voltmeter. A toggle switch is used for channel selection. Green channel and red channel voltage is measured from digital voltmeter by selecting upper and lower connection of toggle switch.

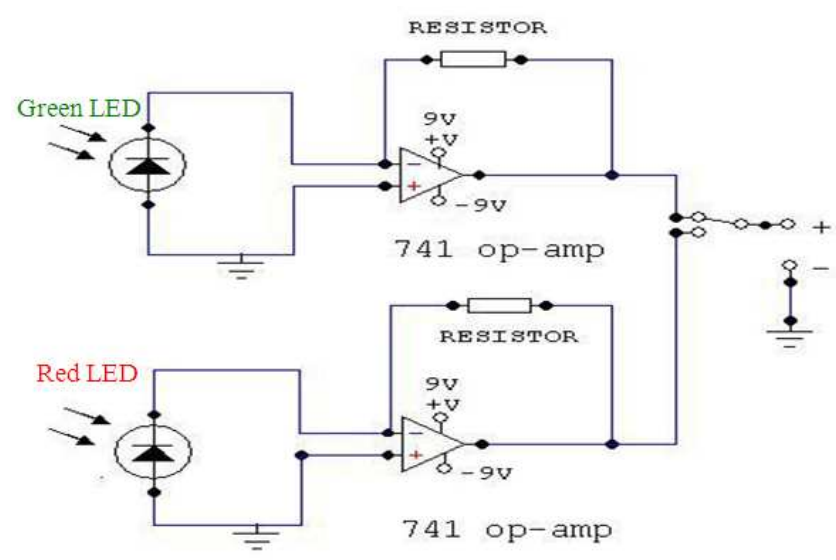

Fig 2. Circuit diagram to construct a LED based handheld sun photometer.

The experimental circuit with battery is enclosed in a wellshaped rectangle case which is made in such a way so that sufficient space remain inside it to set up a battery, PCB 
board, two toggle switches, two LEDs, two terminal posts. In a side wall of the case two holes are made as solar entrance and two end open metallic pipes are used for LED through the holes to avoid unexpected irradiance. An " $L$ " angle bracket including a hole for passing sunlight is added to the upper surface of the case beside the sun light entrance and another "L" angle bracket is also added to the opposite side of the upper surface of the case as solar target. When the sun photometer is pointed to the sun then sunlight falls vertically over the head of the LED. At the same time sunlight also passes through the hole of first angle bracket and enlightens a particular point namely sun target of the second angle bracket which is marked for later measurement. A centimeter scale is set up to the upper surface of the case to measure the shadow length of first "L" angle brackets during measurement. A sprit level is used to make the case surface horizontal so that shadow length can be measured correctly.

\section{Data and Methodology}

\subsection{AOD Retrievals}

The methodology followed for the extraction of the AOD values from the constructed handheld sun photometer measurement depend on some important terms. These are:

i. Solar elevation angle measurement [4]:

$\theta=\tan ^{-1}\left(\frac{y}{x}\right)$; Here, $\mathrm{y}$ is the height of angle bracket, $\mathrm{x}$ is the shadow length measured from scale.

ii. Relative air mass measurement [4]: Relative air mass (m) is a measure of the amount of atmosphere through which a beam of sunlight travels.

$\mathrm{m}=1 / \sin \theta ; \mathrm{m}=$ relative air mass, $\theta=$ solar elevation angle (degree).

iii. Extraterrestrial constant: A sun photometer is considered to be calibrated if its extraterrestrial constant $\left(\mathrm{V}_{\mathrm{o}}\right)$ is known. This is the voltage which would be measured with sun photometer if there were no atmosphere between experimental place and the sun [4].

iv. "Langley plot" method: Samuel Langley pioneered the measurement of sunlight for the Smithsonian Institution. He used BEER'S LAW to measure the extraterrestrial constant $\left(\mathrm{V}_{\mathrm{o}}\right)$ of sunlight at the top of the atmosphere without leaving the surface of Earth [4].

v. Beer's law [4]: $\mathrm{V}=\mathrm{V}_{\mathrm{o}}\left(\mathrm{r}_{\mathrm{o}} / \mathrm{r}\right)^{2} \mathrm{e}-\left[\alpha_{\mathrm{a}}+\alpha_{\mathrm{R}}\left(\mathrm{p} / \mathrm{p}_{\mathrm{o}}\right)\right] \mathrm{m}$ Here,

$\mathrm{V}=$ channel voltage corresponding each of the two channels in $\mathrm{mV}$.

$\mathrm{V}_{\mathrm{o}}=$ the extraterrestrial corresponding each of the two channels in $\mathrm{mV}$.

$r_{o}=$ average Earth-sun distance ( 1 astronomical unit) in AU.

$\mathrm{r}=$ earth-sun distance at the time of a measurement in $\mathrm{AU}$

$\alpha_{a}=$ aerosol optical depth

$\alpha_{R}=$ the Rayleigh scattering [12] by the atmosphere

$\mathrm{p}_{\mathrm{o}}=$ standard air pressure in millibar $(1013.25 \mathrm{mb})$ $\mathrm{p}=$ air pressure at the observing site in millibar

$\mathrm{m}=$ relative air mass

vi. The total atmospheric optical depth $(\alpha)$ consists of three basic parts: molecular (Rayleigh) scattering $\left(\alpha_{\mathrm{R}}\right)$ by the atmosphere, atmospheric absorption by gases $\left(\alpha_{\mathrm{g}}\right)$ such as ozone, and scattering by aerosols $\left(\alpha_{\mathrm{a}}\right)$ (aerosol optical depth, or AOD) [4]:

$$
\alpha=\alpha_{\mathrm{R}}+\alpha_{\mathrm{g}}+\alpha_{\mathrm{a}}
$$

vii. Earth to sun distance during measurement:

$\mathrm{r}=\frac{1-\varepsilon^{2}}{1+\varepsilon \cos \left(360^{\circ} \times d / 365\right)}$ is the earth to sun distance during the date of measurement in AU (astronomical unit), $\mathcal{E}$ is the eccentricity of earth's orbit which value is 0.0167 and $\mathrm{d}$ is the serial number of the particular day

viii. Working formula [4]: $\alpha_{\mathrm{a}}=\left[\ln \left(\mathrm{V}_{\mathrm{o}}\left(\mathrm{r}_{\mathrm{o}} / \mathrm{r}\right)^{2}\right)-\ln (\mathrm{V})-\right.$ $\left.\alpha_{\mathrm{R}}\left(\mathrm{p} / \mathrm{p}_{\mathrm{o}}\right) \mathrm{m}\right] / \mathrm{m}$

\subsection{Data Acquisition}

In the present work the study of the monitoring aerosol in greater Rajshahi division has been studied from $31^{\text {st }}$ May to $14^{\text {th }}$ June in 2012. Experimental data were compared with the data obtained from the NASA's Level-3 product with science-team. Though there are two separate channels have been used in constructed sun photometer at $550 \mathrm{~nm}$ and $625 \mathrm{~nm}$ but no update was not obtained NASA's website at $625 \mathrm{~nm}$. For this we cannot compare AOD at $625 \mathrm{~nm}$ with satellite based measurement. The time of overpass Rajshahi by the Terra and Aqua satellite and there orbital tracks were seen from its websites.

\subsection{MODIS Retrievals}

The MODIS instrument is on board NASA's Earth Observing System (EOS) Terra (EOS AM) and Aqua (EOS PM) satellites [1]. The orbit of the Terra satellite goes from north to south across the equator in the morning and Aqua satellite passes south to north over the equator in the afternoon resulting in global coverage every 1 to 2 days [8]. The EOS satellites have a \pm 55 degree scanning pattern and orbit at $705 \mathrm{~km}$ with a $2,330 \mathrm{~km}$ swath width. MODIS measures the total of solar radiance scattered by the atmosphere and light reflected by the ground surface and attenuated by atmospheric transmission [9]. The intensity of surface reflectance depends on the zenith angle, satellite position and the directional reflectance properties of land cover. The algorithm that generates AOD retrievals uses the MODIS spatial resolution of $250 \mathrm{~m}(660 \mathrm{~nm}$ band) and $500 \mathrm{~m}$ (470 nm and 550nm bands) and produces a statistically robust product in $10 \mathrm{~km} \times 10 \mathrm{~km}$ resolution [6].

\section{Result and Discussion}

\subsection{Calibration}

Before retrieving AOD value using handheld sun photometer calibration is the precondition and the calibrated 
value is different for every sun photometer as well as for every channel [7]. When a channel is calibrated once then no more calibration is needed. In this study our constructed sun photometer was calibrated on $31^{\text {st }}$ May, 2012. In that day the sky condition was almost clear especially from morning to solar noon. Data were taken for calibration at 8:10am to $12: 00 \mathrm{pm}$. By pointing the instrument directly at the sun, the data points are plotted on the graph which falls along or very near a perfectly straight line. Extending this line to where it crosses the y-axis at an air mass of 0 (zero) gives the logarithmic value of the extraterrestrial constant for the instrument.

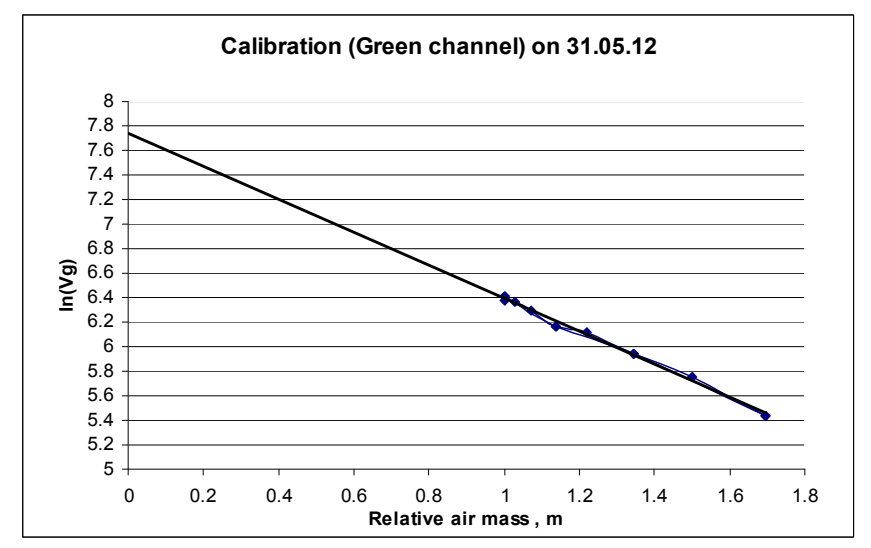

Fig 3. Langley plot for finding extraterrestrial constant of green channel.

To get extraterrestrial constant, logarithmic values of channel voltage at zero relative air mass have to make antilog. Langley plot method for determining extraterrestrial constant of green channel is shown in Fig.3 for green channel and in Fig.4 for red channel.

From Fig. $3 \ln \left(\mathrm{V}_{\mathrm{g}}\right)$ at zero relative air mass is 7.742. So, Extraterrestrial constant of red channel is $2303.0739 \mathrm{mV}$.

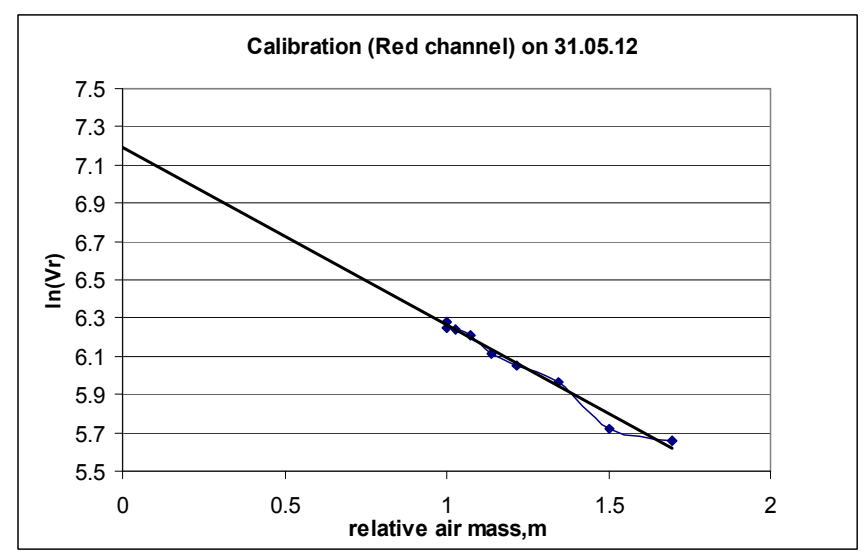

Fig 4. Langley plot for finding extraterrestrial constant of red channel.

From Fig.4 $\ln \left(\mathrm{V}_{\mathrm{r}}\right)$ at zero relative air mass is 7.1878 . So, Extraterrestrial constant of red channel is $1323.188 \mathrm{mV}$. Extraterrestrial constant is a unique value for each channel which is not changed after calibration. It is affected if the feedback resistor value is changed or the connected battery voltage reduces below 7.5 volt.

\subsection{Measured AOD by the Constructed Handheld Sun Photometer for Both Channels}

By using previous calibration AOD was calculated from obtained data of constructed handheld sun photometer are graphically represented in Fig.5 for both green and red channels. The figure represents mean AOD values for each individual day and it is seen that AOD is very high compare to normal value. In the present work data were taken when the natural temperature was very high and there was a heavy lack of rainfall which has caused the increasing the value of aerosol optical depth [1]. Because of less rainfall and excessive heat the concentration of dust, bacteria, salt, pollen, various pollutants in air as well as concentration of aerosol increase [9]. Again aerosol itself is responsible for less rainfall and excessive heat. So its effect is regenerative. Higher AOD denotes lower transmission of sun light, which means higher concentration of aerosol increases attenuation for sun light to reach the earth surface [10]. It is seen from Fig. 5 that AOD for green channel is always high with respect to AOD for red channel and the difference between two channel's AOD is almost same for each day. According MODIS data from Terra and Aqua satellite it is observed same characteristics for different wavelengths. So, it can be conclude that attenuation of sunlight caused by aerosol to reach the earth surface is increased with decreasing the wavelength.

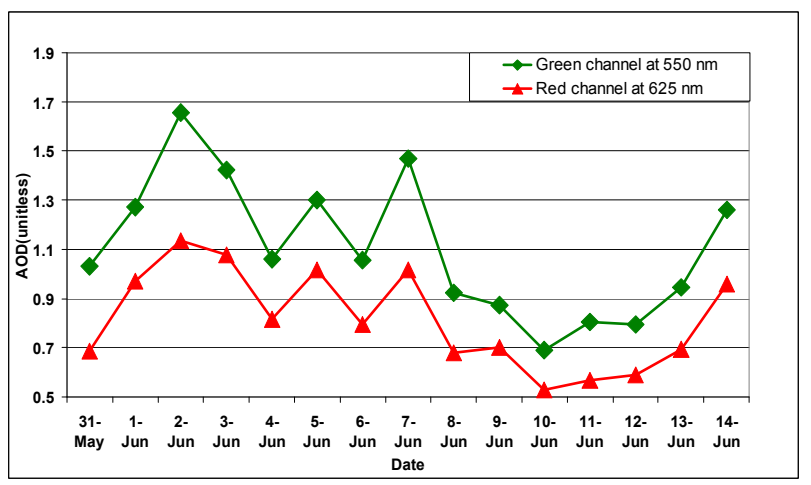

Fig 5. AOD measured at 550nm (Green channel) and 625nm (Red channel) by the handheld sun photometer.

\subsection{Aerosol Optical Depth Comparisons}

Since no AERONET data are available in Rajshahi division, our constructed handheld sun photometer has been used to assess AOD as well as to verify and study the aerosol properties with MODIS data. The MODIS dataset are matched to corresponding readings by handheld sun photometer. Original MODIS and sun-photometer AOD data are used; none of the data are aggregated.

\subsubsection{Constructed Two Channels Handheld Sun Photometer Retrievals}

The handheld sun photometer measures attenuation of the direct sunlight as it passes through the atmosphere. As the aperture of the instrument is small, the light intensity measured by the sun photometer is usually not influenced by 
atmospheric scattering, at least for moderate AOD values. The instrument, therefore, measures the total transmittance from which AOD of the atmosphere is derived. Each time the sun photometer was mounted at a specific location and data were taken within a few second to ensure best results.

\subsubsection{Comparison of AOD between Constructed Handheld Sun Photometer and Terra-MODIS}

Fig. 6 shows the scatter plots of Terra-MODIS AOD versus handheld sun photometer AOD at 550nm (green channel) during of the study period. AOD value was very high during experiment which is discussed previous. It is seen from Fig.6 that on $2^{\text {nd }}$ June'12 AOD was maximum $(\sim 1.65)$ and on $10^{\text {th }}$ June'12 its value was minimum $(\sim 0.7)$ which also higher than expected value. Fluctuation of AOD values according Terra satellite and handheld sun photometer measurement is almost same which denotes well ground based measurement compare with satellite based measurement.

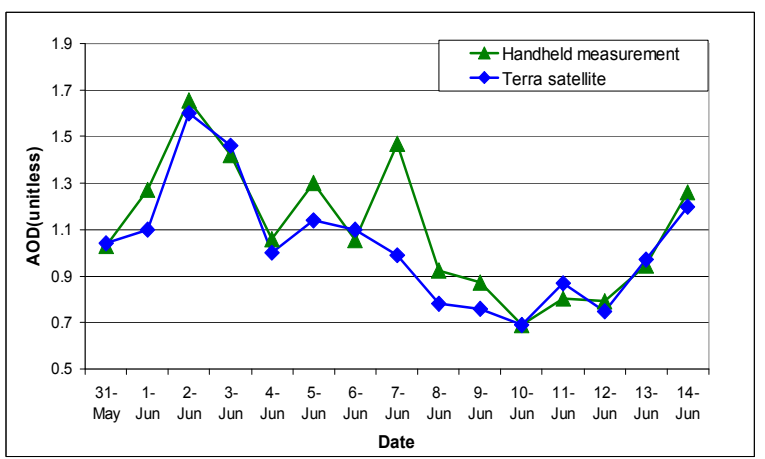

Fig 6. AOD measured at 550nm (Green channel) by constructed handheld sun photometer and Terra satellite.

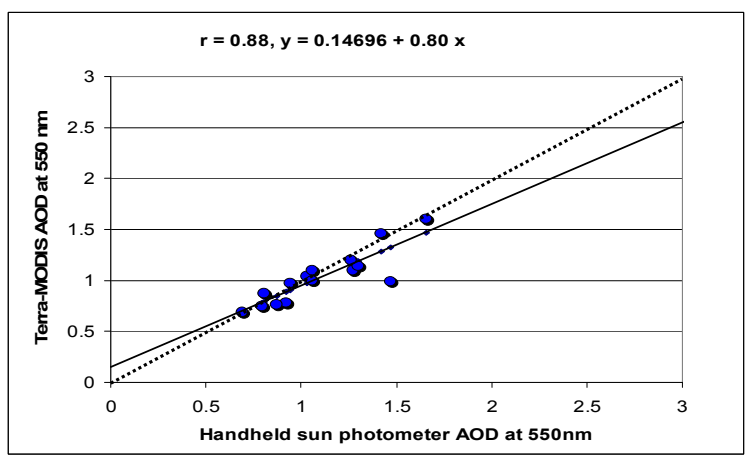

Fig 7. Terra-MODIS aerosol optical thickness retrievals over Rajshahi at $550 \mathrm{~nm}$ as a function of handheld sun photometer observations collocated in space and time. The solid lines represent the slopes of linear regression and the dashed lines are the 1:1 lines. The regression equation, the correlation coefficient is given at the top of the plot.

Fig.7 is x-y scatter plot of measurements made by the constructed handheld sun photometer at clear or nearly clear sky. Measurement with this sun photometer is strongly correlated with MODIS where correlation co-efficient is $\mathrm{r}=$ 0.88. In the following figure the dashed line denotes the equal axis plot. The regression equation and the correlation coefficient are given top of the plot. The slope of experimented AOD and dashed line of equal axis is almost nearer. However, Terra-MODIS seem to underestimate AOD relative to sun photometer, and the regressed slope $(0.80)$ is lower than unity. The deviation from unity of the slope of the correction line represents systematic biases, which could be caused by the incorrect assumptions of aerosol optical properties, and some other factors.

\subsubsection{Comparison of AOD between Constructed Handheld Sun Photometer and Aqua-MODIS}

AOD at $550 \mathrm{~nm}$ (green channel) measured from constructed handheld sun photometer and Aqua-MODIS satellite is graphically presented in Fig.8. It is seen from figure that according Aqua satellite measurement AOD was maximum $(\sim 1.7)$ on 31 st May'12 and minimum $(\sim 0.8)$ on 10th June'12 whereas the handheld sun photometer measurements are about 1.0 and 0.7 respectively, which is less well compare with Terra satellite measurement. Fluctuation of AOD according Terra satellite and handheld sun photometer measurement is almost same though its starting portion is inversely related. Fig. 9 is $x-y$ scatter plot of measurements made by the handheld sun photometer at clear or nearly clear sky. Measurement with the present sun photometer is less well correlated $(\mathrm{r}=0.55)$ with AquaMODIS than Terra-MODIS. In the following figure the dashed line denotes the equal axis plot. The regression equation and the correlation coefficient are given top of the plot. The slope of experimented AOD and dashed line of equal axis is almost less nearer than Terra-MODIS.

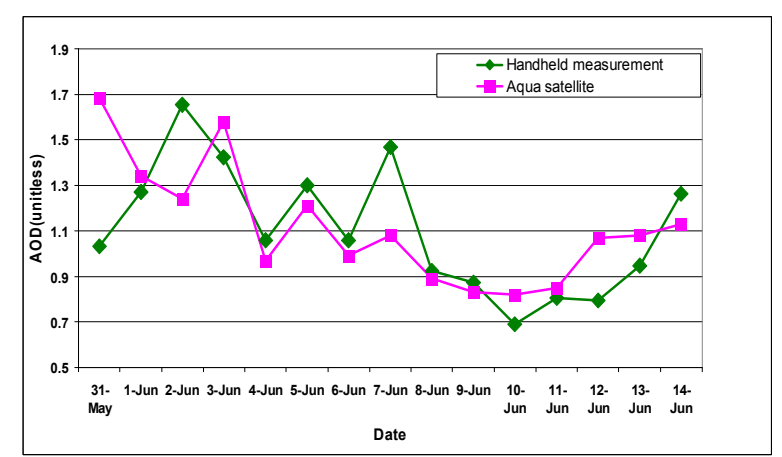

Fig 8. AOD measured at 550nm (Green channel) by handheld sun photometer and Aqua satellite.

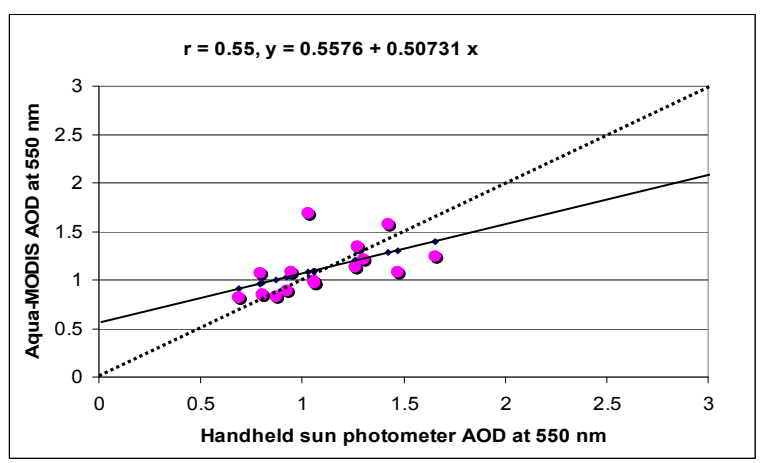

Fig 9. Aqua-MODIS aerosol optical thickness retrievals over Rajshahi at $550 \mathrm{~nm}$ as a function of handheld sun photometer observations collocated in space and time. The solid lines represent the slopes of linear regression and the dashed lines are the 1:1 lines. The regression equation, the correlation coefficient is given at the top of the plot. 


\subsubsection{Comparisons between Terra-MODIS and Aqua- MODIS AOD Retrievals}

Fig.10 shows the time series plot of Terra and Aqua MODIS AOD values at $550 \mathrm{~nm}$. The both satellite AOD values reveal good association with some deviations. Sometimes the two satellites AOD values show opposite variations such as on $31^{\text {st }}$ May, $1^{\text {st }}, 2^{\text {nd }}$ and $12^{\text {th }}$ June, 2012. The correlation coefficient between Terra and Aqua MODIS is $r=0.65$. Terra satellite is used to study aerosol pollution whereas Aqua satellite observes for the precipitation, evaporation, and cycling of water. For this the priority of Terra-MODIS is greater than Aqua-MODIS in observing AOD over land. Also Aqua satellite observes for aerosol properties.

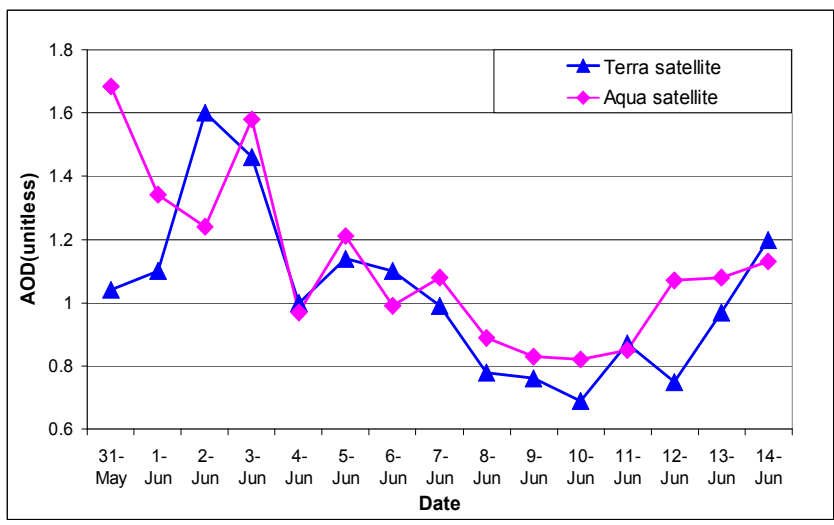

Fig 10. AOD measured by Terra \& Aqua satellite at 550nm.

\section{Conclusion}

An overall study for assessing AOD over Rajshahi division for 15 days of June 2012 is presented in this paper where satellite and constructed handheld sun photometer data are used. The validation of MODIS AOD retrievals and ground based measurement are presented for the first time in Bangladesh. After comparison it is found that MODIS AOD data are within the expected accuracy as reported by NASA with our obtained AOD by the sun photometer. For continuous monitoring of AOD of any region AERONET is essential but in our country it is rather sparse. Nowadays, monitoring climate is very important because we are becoming victims of many natural calamities in every year. Our constructed handheld sun photometer is very less expensive and easy to use but its result is significant to study the atmospheric aerosols. It is a ground based AOD measurements with a spatial resolution which is not achieved by professional instruments. Solar radiance measurements are done with two LEDs, one in the green wavelength range with effective wavelength of 550nm and the other in the red wavelength range with effective wavelength of $625 \mathrm{~nm}$. AOD measured at 550nm (green channel) and 625nm (red channel) by the handheld sun photometer vary in same manner while green channel is always overestimated the red channel. The correlation coefficient between the constructed handheld sun photometer and MODIS satellites for green channel (550nm) in greater Rajshahi are $r=0.88$ (Terra) and $r=0.55$ (Aqua). The correlation of Terra-MODIS with Aqua-MODIS was $r=$ 0.65 which is less than the correlation coefficient with the measured value of constructed sun photometer. The good association of sun photometer with Terra-MODIS than AquaMODIS may be cause of the time difference in the comparisons. Terra satellite overpasses occur before noon, and Aqua satellite overpasses occur after noon, when the sky is generally more turbid. This could explain increased scatter in the Aqua satellite comparisons that might not be discernable in satellite observations over a much larger area. For measuring actual AOD by sun photometer cloudless sky is needed to enlighten the LED vertically by sun ray. If the sky becomes cloudless then it can be found out how the solar radiation is attenuated by aerosol. But during this experimental season it was rear. Another important point is that to find out actual AOD data must be collected for whole day, because relative air mass changes rapidly during morning and afternoon. The major finding is that AOD data by handheld constructed sun photometer provide relatively accurate information of the aerosol loading, in terms of aerosol optical depth by MODIS, over Rajshahi. However, more research works on this topic in different tropical regions with a longer time series is needed to validate of these results.

\section{Acknowledgements}

We would like to thank the NASA MODIS aerosol team for providing MODIS satellite data. We also thank World Weather Online and Meteo Group UK for providing regular air pressure, temperature and weather update of experimental region.

\section{Research Highlights}

- Construction cost of LED based handheld sun photometer is relatively very low compare with sun photometer that uses interference filter.

- Obtained AOD by constructed handheld sun photometer are compared with MODIS data of Terra and Aqua satellite.

- Good correlation is found from examined data after comparison which denotes measurement reliability.

\section{References}

[1] A. Retalis, D. G. Hadjimitsis, S. Michaelides, F. Tymvios, N. Chrysoulakis, C. R. I. Clayton, and K. Themistocleous, 2010: Comparison of aerosol optical thickness with in situ visibility data over Cyprus. Nat. Hazards Earth Syst. Sci., 10, 421-428.

[2] D.G. Kaskaoutis, N. Sifakis, A. Retalis, and H. D. Kambezidis, 2010: Aerosol Monitoring over Athens Using Satellite and Ground-Based Measurements. Advances in Meteorology, Volume 2010 (2010), Article ID 147910, 12 pages, doi:10.1155/2010/147910. 
[3] YANG Jing-Mei, QIU Jin-Huan, and ZHAO Yan-Liang, 2010: Validation of Aerosol Optical Depth from Terra and Aqua MODIS Retrievals over a Tropical Coastal Site in China. ATMOSPHERIC AND OCEANIC SCIENCE LETTERS, VOL. 3, NO. 1, 36-39.

[4] David R. Brooks, 2006: Monitoring Solar Radiation and Its Transmission Through the Atmosphere. Research Professor, Department of Mechanical Engineering and Mechanics, Drexel University, Philadelphia, PA USA, President, Institute for Earth Science Research and Education, Norristown, PA USA, The GLOBE Program's Aerosols, Water Vapor, and UVA Monitoring Projects.

[5] Forrest M. Mims III: An Inexpensive and Accurate Student Sun Photometer with Light-Emitting Diodes as Spectrally Selective Detectors. Sun Photometer Atmospheric Network, 433 Twin Oak Road, Seguin, Texas 78155 USA.

[6] E. Gerasopoulos, V. Amiridis, S. Kazadzis, P. Kokkalis, K. Eleftheratos, M. O. Andreae, T. W. Andreae,H. El-Askary, and C. S. Zerefos, 2011: Three-year ground based measurements of aerosol optical depth over the Eastern Mediterranean: the urban environment of Athens. Atmos. Chem. Phys., 11, 2145 2159, doi: 10.5194/acp-11-2145-2011.

[7] Joris de Vroom, October 2003: The Contribution of Dutch GLOBE Schools to Validation of Aerosol Measurements from Space. Vrije Universiteit Amsterdam.

[8] V. Buchard, C. Brogniez, F. Auriol, T. Podvin, L. Blarel: Comparisons between ground-based and satellite retrievals in the UV range. LOA, Université des Sciences et Technologies de Lille, France.

[9] YORAM J.KAUFMAN, 1993: Aerosol Optical Thickness and Atmospheric Path Radiance. Laboratory for Atmospheres, NASA Goddard Space Flight Center, Greenbelt, Maryland.
JOURNAL OF GEOPHYSICAL RESEARCH, VOL.98, NO.D2, PAGES 2677-2692.

[10] M. Shekar Reddy, Olivier Boucher, Nicolas Bellouin, Michael Schulz, Yves Balkanski, Jean-Louis Dufresne, and Mai Pham, 2005: Estimates of global multicomponent aerosol optical depth and direct radiative perturbation in the Laboratoire de Me'te'orologie Dynamique general circulation model. JOURNAL OF GEOPHYSICAL RESEARCH, VOL. 110, D10S16, doi: 10.1029/2004JD004757.

[11] Jun Wang and Sundar A. Christopher, 2003: Intercomparison between satellite-derived aerosol optical thickness and PM2.5mass: Implications for air quality studies. Department of Atmospheric Sciences, University of Alabama in Huntsville, Huntsville, Alabama, USA, GEOPHYSICAL RESEARCH LETTERS, VOL.30, NO.21,2095, doi:10.1029/2003GL018174.

[12] BARRYA. BODHAINE, NORMANB. WOOD, ELLSWORTHG. DUTTON, JAMESR. SLUSSER, 1999: On Rayleigh Optical Depth Calculations. Cooperative Institute for Research in Environmental Sciences, NOAA/Climate Monitoring and Diagnostics Laboratory,Boulder, Colorado, NOAA/Climate Monitoring and Diagnostics Laboratory, Boulder, Colorado.

[13] J. Gr"obner, R. Vergaz, V. E. Cachorro, D. V. Henriques, K. Lamb, A. Redondas, J. M. Vilaplana, and D. Rembges, 2001: Intercomparison of aerosol optical depth measurements in the UVB using Brewer spectrophotometers and a Li-Cor spectrophotometer. GEOPHYSICAL RESEARCH LETTERS, VOL. 28, NO. 9, PAGES 1691-1694.

[14] Chiara Levoni, Marco Cervino, Rodolfo Guzzi, and Francesca Torricella, 1997: Atmospheric aerosol optical properties: a database of radiative characteristics for different components and classes. Vol. 36, No. 30/ APPLIED OPTICS. 